\title{
Special issue: bioenergy
}

\author{
Don-Hee Park $\cdot$ Sang Yup Lee
}

Published online: 11 December 2011

(C) Springer-Verlag 2011

Due to our increasing concerns on climate change and limited fossil resources, bio-based production of chemicals, fuels, and materials has been drawing much attention worldwide. The Korean government announced "Low carbon, green growth" as the most important national agenda in 2008. It is believed that biotechnology will be playing increasingly important roles in achieving green growth of the world.

The 2011 international symposium on bioenergy Korea was held on 17-18 March 2011. This special issue contains 41 selected papers among those presented at the conference. The topics covered include, but not limited to, biomass cultivation, biomass pretreatment, and biomass conversion in the field of bioenergy. Also, several papers on general enzyme technology and bioconversion processes are presented. As the field of bioenergy is rapidly moving forward with rather traditional bioethanol and biodiesel to more advanced biofuels, it is expected that new emerging technologies around bioenergy will continuously appear in the coming years.
Most of the papers in this special issue are contributed by Korean biotechnologists, and thus should provide readers with some glimpse on research activities around bioenergy in Korea. This year's symposium focused in particular on bioprocessing aspects of bioenergy. The next year's symposium is expected to cover broader spectrum of bioenergy research, and will also cover more stories on advanced biofuels such as biobutanol and alkanes.

We are facing a grand challenge on how to move toward bio-based sustainable society. We, biotechnologists, will be a key player in overcoming this challenge by providing solutions to achieve cost-effective production of biofuels and to realize sustainable bio-based chemical industries.

Last but not least, we would like to thank all the contributors to this special issue and also the anonymous reviewers who kindly provided nice comments to improve the manuscripts. It is hoped that another special issue covering the state-of-the art bioenergy research will be published in the future. We hope that you will enjoy reading the papers presented in the special issue.

\footnotetext{
D.-H. Park $(\square)$

Interdisciplinary Program of Graduate School for Bioenergy and Biomaterials, Chonnam National University,

Gwangju, Republic of Korea

e-mail:dhpark@jnu.ac.kr

S. Y. Lee $(\bowtie)$

Department of Chemical and Biomolecular Engineering, KAIST,

Daejeon, Republic of Korea

e-mail: leesy@mbelmail.kaist.ac.kr
} 